\title{
Fatores associados ao desempenho escolar em Português: um estudo multinivel por regiões
}

\author{
Jacob Arie Laros* \\ João Luiz Marciano"* \\ Josemberg Moura de Andrade
}

\section{Resumo}

No presente estudo objetivou-se identificar quais caracteristicas de alunos e escolas são associadas ao desempenho em Português, bem como verificar se existem diferenças entre as regiões geográficas brasileiras. Foram analisados os dados de 33.962 alunos da $3^{\text {a }}$ série do Ensino Médio, distribuídos em 1.661 escolas brasileiras pesquisadas no $\mathrm{SAEB} / 2001$. Entre as variáveis de controle, a maior contribuição para o modelo final foi da variável nível socioeconômico da escola. Pelo menos $41 \%$ da variância do nível da escola e $14 \%$ da variância do nível do aluno foram explicados no modelo multinivel final. Concluí-se que a desigualdade entre regiões do Brasil em relação ao desempenho médio das escolas em Língua Portuguesa, é fortemente relacionada com o nível socioeconômico dos alunos e das escolas.

Palavras-chave: Desempenho escolar. Regressão. Análise multinivel. Região geográfica.

\section{Factors associated with school performance in Portuguese Language: a multilevel study by geographic regions}

\section{Abstract}

The purpose of the present study was to identify which characteristics of students and schools affect proficiency in Portuguese Language, as well as to verify the existence of differences between Brazilian regions in this respect. The data were analyzed of 33,962 third grade students nessed in 1,661 secondary schools who participated in the 2001 assessment of the SAEB. Among the control variables, socioeconomic status of the

\footnotetext{
* Doutor PhD em Personality and Educational Psychology pela University of Groningen; Professor do Instituto de Psicologia da Universidade de Brasília; E-mail: jalaros@gmail.com.

** Doutor em Ciência da Informação pela Universidade de Brasília; Analista de Informática Legislativa da Câmara dos Deputados; E-mail: marciano@unb.br.

**** Doutor em Psicologia Social, do Trabalho e das Organizações pela Universidade de Brasília; Professor adjunto do Departamento de Psicologia da Universidade Federal da Paraíba;

E-mail: josemberg.andrade@gmail.com.
} 
school had the strongest contribution to the final model. At least $41 \%$ of the school level variance and $14 \%$ of the student level variance were explained in the final multilevel model. It can be concluded that the inequality between Brazilian regions in relation to the performance of schools in Portuguese Language is strongly related to the socioeconomic status of the students of the schools.

Keywords: School performance. Regression. Multilevel analysis. Geographic region.

\section{Factores relacionados con el rendimiento escolar en Lengua Portuguesa: un estudio multinivel por regiones.}

\section{Resumen}

El presente estudio tiene por objeto identificar qué características de los alumnos y de las escuelas se asocian al rendimiento en Lengua Portuguesa, y verificar si existen diferencias entre las regiones geográficas brasileñas. Para tal efecto se analizaron los datos de 33.962 alumnos del $3^{\circ}$ año de la enseñanza secundaria, distribuidos en 1.661 escuelas brasileñas analizadas en la evaluación de 2001 hecha por el SAEB (Sistema de Evaluación de la Educación Básica). Entre las variables de control, la mayor contribución para el modelo final fue la variable nivel socioeconómico de la escuela. Por lo menos el $41 \%$ de la varianza del nivel de la escuela y el $14 \%$ de la varianza del nivel de alumno se explicaron en el modelo multinivel final. Así se concluye que la desigualdad entre las regiones de Brasil, referente al rendimiento medio de las escuelas en Lengua Portuguesa, se relaciona bastante con el nivel socioeconómico de los alumnos y de las escuelas.

Palabras clave: Rendimiento escolar. Regresión. Análisis multinivel. Región geográfica.

\section{Introdução}

A sociedade contemporânea no Brasil vê-se desafiada a responder às demandas por melhorar a qualidade da educação, principalmente para as escolas públicas de Ensino Fundamental e Médio. Para conseguir aumentar o nivel de desempenho escolar dos alunos, precisam ser desenvolvidas políticas públicas que tenham impacto positivo no aprendizado do alunado. Os fatores que impactam no desempenho cognitivo dos alunos podem ser categorizados em quatro grandes eixos: projetos pedagógicos, a estrutura escolar, a família e características do próprio aluno (SOARES; ALVES, 2003). A questão a respeito de quais são os fatores dentro de cada categoria que têm mais potencial para aumentar o desempenho escolar dos alunos brasileiros é um dos objetivos principais das avaliações em larga escala como, por exemplo, o Sistema Nacional de Avaliação da Educação Básica (SAEB), a Prova Brasil, o Exame Nacional do Ensino Médio (ENEM) e o Exame Nacional de Desempenho de Estudantes (ENADE). Além das avaliações nacionais, 0 Brasil também participa de avaliações educacionais internacionais (WOLFF, 2004) como, por exemplo, PISA (Program for International Student Assessment). 
No Brasil, desde o final dos anos 90, a técnica de modelos hierárquicos lineares começou a ser utilizada com maior frequência para interpretar e analisar os dados das avaliações educacionais em larga escala (ANDRADE; LAROS, 2007; FLETCHER, 1998; SOARES, 2005; SOARES; ALVES, 2003). Os modelos hierárquicos lineares devem ser utilizados sempre que os dados a serem analisados têm uma estrutura hierárquica, ou seja, quando os dados são coletados de indivíduos que são alocados em grupos ou contextos, uma situação bastante comum nas pesquisas educacionais. 0 uso crescente desta técnica foi estimulado pela maior disponibilidade de pacotes estatísticos no mercado, como MLwiN (RASBASH et al., 2005) e HLM (Hierarchical Linear Models) (BRYK; RAUDENBUSH, 2002). Os modelos hierárquicos lineares também são conhecidos por outras denominações, tais como: modelos de regressão multinivel, modelos lineares de coeficientes randômicos, modelos lineares mistos e análise de regressão multinivel. 0 termo linear indica que os modelos hierárquicos lineares são associados a modelos lineares bem conhecidos, como regressão tradicional, análise de variância (ANOVA) e análise de covariância (ANCOVA). 0 termo aleatório significa que os coeficientes de regressão nos modelos multinivel não precisam ser iguais para todas as unidades do nivel macro. A fim de reconhecer explicitamente o contexto de grupo das observações, a análise de regressão multinivel leva em conta a correlação intraclasse (ICC - intraclass correlation), produzindo erros padrão de coeficientes que levam em conta o chamado efeito de delineamento. Kish (1965) define o efeito de delineamento como a razão entre a variância efetiva da amostra e a variância observada.

Fletcher (1998) foi um dos primeiros pesquisadores no Brasil que utilizou análise de regressão multinivel com dados de avaliação educacional em larga escala. 0 pesquisador analisou a base de dados nacional de SAEB de 1995 da prova de Matemática de 14.704 alunos da $8^{a}$ série do Ensino Fundamental. 0 pesquisador enfatizou a necessidade de ajustar os resultados das provas do SAEB pelas diferenças na composição social do alunado das escolas. Ele argumentou que para identificar as características das escolas que são associadas com um bom desempenho escolar é necessário levar em conta o ambiente familiar do aluno e o nível socioeconômico (NSE) da comunidade em torno da escola. Fletcher (1998) relatou uma ICC bruta de 0,31 e uma ICC corrigida pelo NSE médio da escola e outras variáveis de composição e seleção de 0,14. A ICC corrigida de 0,14 indica que depois da inserção das variáveis de controle ainda 14\% da variância total podem ser atribuídos ao nível de escola. Assim, restou suficiente variabilidade entre as escolas para identificar fatores no nivel macro associados ao desempenho escolar. Fletcher (1998) observou que 63\% da variância entre as escolas no desempenho em Matemática eram atribuídas à seletividade de ordem socioeconômica das escolas e somente $1 \%$ da variância no nível micro era explicada pelo NSE do aluno. 0 autor chegou à conclusão de que a associação entre o desempenho em Matemática e os fatores socioeconômicos é muito mais forte no nível da escola do que no nível de alunos e que o papel distributivo interno da escola em termos do NSE é muito limitado. Portanto, o conhecimento do NSE médio é extremamente importante para prever o desempenho médio da escola em Matemática. Fletcher (1998) sugeriu que os alunos não conseguem 
perceber o efeito seletivo do NSE uma vez que praticamente todo seu impacto ocorre entre escolas às quais eles não têm acesso. As análises de Fletcher apontaram para efeitos positivos, sobre o desempenho em Matemática, da proporção na escola de alunos do sexo masculino e de cor branca. 0 modelo final do estudo de Fletcher explicou no mínimo $38,9 \%$ da variância do nível da escola e 6,5\% do nível do aluno tomando como referência o modelo depois da inserção das variáveis de controle.

Barbosa e Fernandes (2000) utilizaram a técnica de regressão multinivel para analisar os dados coletados no SAEB de 1997, abrangendo 2.821 alunos da 8a série do Ensino Fundamental da região Sudeste, aos quais foi aplicada a prova de Matemática. A ICC bruta nesse estudo foi de 0,37 e uma ICC de 0,30 corrigida pelo nível da educação do pai, indicando que, depois da inserção da variável de controle, $30 \%$ da variância podem ser atribuídos ao nivel de escola. A ICC corrigida relativamente alta de 0,30 nesse estudo é uma indicação de que a variável "nível da educação do pai" não foi capaz de captar toda a variância associada ao NSE da família. Depois de inserir a variável de controle, os autores observaram que a variância do intercepto entre escolas caiu em $27,4 \%$. Os autores afirmaram que este achado confirma que a distribuição dos alunos pelas escolas não é aleatória. As análises de Barbosa e Fernandes (2000) apontaram para um desempenho pior das meninas em Matemática e um desempenho melhor dos alunos de escolas privadas. Tomando como referência o modelo depois da inserção da variável de controle, o modelo final deste estudo conseguiu explicar, no mínimo, 33,7\% da variância do nível da escola e 2,2\% do nível do aluno.

Soares e Alves (2003) pesquisaram as desigualdades raciais no sistema brasileiro de educação básica utilizando a análise de regressão multinivel. Os autores analisaram a base de dados, referente à prova de Matemática da $8^{a}$ série do Ensino Fundamental, do SAEB 2001. A base de dados tinha as respostas de 50.300 alunos de 4.056 escolas. No nível micro, foram incluídas como variáveis de controle, o NSE do aluno e o atraso escolar, e, no nível macro, foram incluídas o NSE médio, o atraso escolar médio e a rede escolar. Os autores também incluíram a variável atraso escolar como um indicador da proficiência prévia do aluno. No modelo básico, no qual os efeitos das variáveis de controle foram retirados, a diferença entre o desempenho de alunos brancos e negros na prova de Matemática foi de 10 pontos na escala do SAEB. Antes da entrada das variáveis de controle, a diferença entre o desempenho de alunos brancos e negros na prova foi de quase 28 pontos. Os autores relatam que a qualificação e o salário dos docentes têm efeito na diferença de desempenho entre alunos brancos e negros, no sentido de aumentar o hiato no desempenho escolar desses grupos. Quanto melhor a qualificação e quanto mais elevado o salário do docente, tanto maior a diferença entre alunos brancos e negros. Entre fatores escolares foi observada a mesma tendência. Escolas mais bem equipadas e com diretores mais envolvidos estão associadas com um aumento da média do desempenho escolar em Matemática, mas aumentam também as diferenças raciais. Os resultados deste estudo mostram que a melhoria das condições de ensino pode contribuir para elevar a média do 
desempenho escolar, mas, ao mesmo tempo, pode aumentar as diferenças entre alunos brancos e negros. Aparentemente, os alunos negros não usufruem as melhorias da escola tanto quanto os alunos brancos (SOARES; ALVES, 2003).

Em um estudo que objetivou identificar as características associadas com o desempenho acadêmico, Jesus e Laros (2004) analisaram os dados de 49.075 alunos da $8^{a}$ série de Ensino Fundamental que fizeram a prova de Língua Portuguesa do SAEB em 2001. Nesse estudo foi encontrada uma ICC bruta de 0,35 e uma ICC corrigida pelas variáveis de controle de 0,10 . Como variáveis de controle no nível micro, entraram na modelagem o NSE da família do aluno, a escolaridade do pai e a etnia do aluno. Como variáveis de controle do nível macro, foram incluídas as mesmas variáveis do nível do aluno agregadas para o nível da escola. Nesse estudo, 0 indice que representa o NSE do aluno foi obtido por meio de análise de componentes principais (ACP) e foi composto de 13 itens do questionário contextual aplicado junto com a prova de Português. As outras variáveis de controle (escolaridade do pai e etnia do aluno) foram baseadas em uma única questão do questionário contextual.

Uma primeira conclusão do estudo de Jesus e Laros (2004) tem relação com o grande impacto das variáveis relacionadas à composição socioeconômica das escolas sobre o desempenho na prova de Português: 79\% da variância entre as escolas devem-se às variáveis de controle. Este resultado é consistente com os valores achados por outros estudos multinivel realizados com os dados das provas do SAEB (BARBOSA; FERNANDES, 2000; SOARES, 2004; SOARES; CESAR; MAMBRINI, 2001; SOARES; ALVES, 2003). Depois de controlar para o efeito do NSE médio da escola, o conhecimento do NSE individual do aluno aparentemente ajuda muito pouco a prever o seu desempenho em Português.

Após o controle das variáveis relacionadas com a seletividade e a composição escolar, a análise de regressão multinivel permitiu a identificação de sete variáveis do nível da escola e quatro variáveis do nível do aluno. No nível micro, as seguintes variáveis mostraram um efeito significativo no desempenho em Português: (1) o grau de regularidade da trajetória escolar; (2) a frequência com que o aluno faz o dever de casa; (3) o grau em que o aluno pode se dedicar integralmente às atividades da escola e (4) quanto o aluno recebe como cobrança e ajuda dos pais. No nível macro foram encontrados os seguintes índices com impacto positivo no desempenho em Português: (1) a frequência com que os professores passam e corrigem a lição de casa; (2) o grau de manutenção e utilização de recursos técnico-pedagógicos da escola; (3) a percentagem de alunos na turma cujos pais apoiam, incentivam e conversam com eles sobre assuntos diversos; (4) a percentagem de alunos na turma que só estudam e não têm vínculo trabalhista; (5) o quanto os professores são comprometidos com a aprendizagem dos alunos; (6) o quanto os professores têm altas expectativas em relação ao desempenho dos alunos, e (7) o estado de conservação das instalações 
físicas na escola. Tomando como referência o modelo depois da inserção das variáveis de controle, o modelo final nesse estudo conseguiu explicar no mínimo 36,5\% da variância do nível macro e 9,2\% da variância no nível micro (JESUS; LAROS, 2004).

Andrade e Laros (2007) analisaram quais caracteristicas de alunos e escolas são associadas ao desempenho escolar, utilizando uma base de dados de 72.379 alunos de 3a série de Ensino Médio que fizeram a prova de Matemática ou a prova de Língua Portuguesa do SAEB em 2001. Nesse estudo de regressão multinivel, os autores acharam uma ICC bruta de 0,46 e uma ICC corrigida de 0,17, indicando que $17 \%$ da variância no desempenho escolar podem ser atribuídos ao nivel de escola e o restante da variância (83\%) ao nível dos alunos. Como variáveis de controle no nivel micro foram incluídas o NSE da família do aluno, o gênero do aluno e a etnia do aluno. Como variáveis de controle do nível macro foram incluídas o NSE médio dos alunos, a percentagem de meninos e a percentagem de alunos não brancos ou não asiáticos. 0 índice que representa o NSE do aluno foi construído através de Análise de Componentes Principais e foi composto por 16 itens do questionário contextual aplicado junto com as provas de Matemática e Língua Portuguesa do SAEB de 2001.

0 efeito da composição socioeconômica e da seletividade da escola sobre o desempenho acadêmico médio das escolas, encontrado no estudo de Andrade e Laros (2007), foi muito forte: $76 \%$ da variância entre as escolas podem ser atribuídos a estas variáveis. Após o controle do NSE e outras variáveis relacionadas com a seletividade e composição escolar, sete índices foram encontrados associados com o desempenho escolar no nível do aluno e dez índices no nível da escola. No nível do aluno, os seguintes índices mostraram um efeito positivo no desempenho escolar: (1) o grau de regularidade da trajetória escolar; (2) o quanto o aluno se compara positivamente com os colegas da turma em relação ao seu desempenho escolar; (3) a falta de cobrança dos pais para fazer lição de casa; (4) o quanto o aluno gosta de estudar Língua Portuguesa ou Matemática; (5) a quantidade de recursos culturais na familia do aluno; (6) a frequência com que o aluno faz o dever de casa; (7) o grau em que o aluno pode dedicar-se exclusivamente às atividades da escola. No nível da escola, os seguintes índices mostraram uma relação positiva com o desempenho escolar: (1) nível médio de recursos culturais na família dos alunos; (2) proporção dos alunos com trajetória escolar regular; (3) falta de cobrança dos pais quanto à lição de casa; (4) proporção dos alunos com dedicação exclusiva nas atividades escolares; (5) clima disciplinar na escola; (6) trabalho colaborativo entre os membros da equipe escolar; (7) manutenção e utilização de recursos técnico-pedagógicos; (8) quantidade de alunos na turma, que fazem a lição de casa e (9) grau de experiência do professor. É importante observar que, exceto pelas variáveis (6), (7) e (9), os valores foram obtidos por agregação. 0 modelo final deste estudo conseguiu explicar, pelo menos, 37,2\% da variância do nível macro e $14,7 \%$ da variância no nível micro, tomando como referência o modelo depois da inserção das variáveis de controle. 
Em um estudo de Soares (2005) empregou-se uma análise de regressão multinível de três níveis hierárquicos para analisar quais fatores são associados ao desempenho dos alunos de $4^{a}$ série do Ensino Fundamental na prova de Língua Portuguesa de 2002 do Programa de Avaliação da Educação Básica (PROEB) do Estado de Minas Gerais. Nesse estudo, os dados de 2.438 escolas, 6.286 turmas e 161.904 alunos foram analisados. Soares (2005) utilizou na construção de modelos hierárquicos a estratégia bottum-up, isto é, parte-se do modelo nulo e vá-se incluindo as variáveis do primeiro nível (nível dos alunos), segundo nível (nível das turmas) e terceiro nível (nível das escolas). Nesse estudo, a ICC bruta tomou o valor de 0,43 , mas o autor não informou o valor da ICC corrigida pelas variáveis de controle, a saber: NSE, atraso escolar, gênero do aluno e etnia do aluno. Depois da inserção das variáveis de controle, três variáveis do nível micro entraram no modelo, a saber: (1) se a família do aluno recebe Bolsa Escola; (2) o número de anos do aluno na pré-escola; e (3) a frequência com que o aluno faz dever de casa. É interessante notar que o efeito da Bolsa Escola é negativo: alunos que possuem Bolsa Escola tendem a apresentar uma proficiência bem inferior aos que não a possuem. Este resultado não deve ser interpretado erradamente no sentido de que a Bolsa Escola causa um desempenho fraco em Língua Portuguesa. 0 efeito negativo está associado à baixa condição social desse tipo de aluno. Aparentemente, o nivel de conhecimento de Língua Portuguesa dos alunos que entraram na escola com uma Bolsa Escola é menor do que o de outros alunos com um NSE similar. No nível da turma as seguintes variáveis mostraram um efeito significativo sobre o desempenho em Português: (1) se o professor passa dever de casa; (2) o grau de exigência do professor; (3) a motivação média da turma dos alunos; (4) o grau de dedicação e disponibilidade do professor, e, por fim (5) a quantidade de faltas do professor na sala de aula. No nível da escola as seguintes variáveis mostraram efeito significativo, e relevante, sobre o desempenho em Português: (1) a percentagem na escola de professores que participam de formação continuada; (2) a quantidade de equipamentos de informática na escola e (3) a idade média dos professores na escola. Quanto à influência da última variável, aparentemente, quanto mais velhos os professores da escola, tanto menor o desempenho dos alunos em Português. Sugere-se que novos estudos sejam realizados a fim de compreender melhor e efeito dessa variável sobre o desempenho escolar.

Sumarizando as pesquisas realizadas no Brasil entre 1998 e 2007, com o uso de análise multinivel, anteriormente relatadas, pode-se afirmar que valores altamente diferenciados da ICC incondicional (sem controle pelas variáveis relacionadas à composição e seletividade escolar) foram encontrados, variando de 0,31 (FLETCHER, 1998) a 0,46 (ANDRADE; LAROS, 2007). Os valores da ICC condicional (após controle pelas variáveis relacionadas à composição e seletividade escolar) mostram ainda mais variabilidade: eles variam entre 0,10 (JESUS; LAROS, 2004) e 0,30 (BARBOSA; FERNANDES, 2000). Praticamente todos os valores corrigidos estão em concordância com os valores relatados por Ferrão e Fernandes (2003) e são compatíveis com os valores de 0,12 a 0,18 relatados nos trabalhos internacionais (CREEMERS; SCHEERENS, 1994). 
Essas pesquisas têm em comum uma quantidade relativamente baixa de variância explicada no nível do aluno, entre 2,2\% (BARBOSA; FERNANDES, 2000) e 14,7\% (ANDRADE; LAROS, 2007). Isso ocorre, entre outras coisas, em decorrência da falta de dados sobre características individuais dos alunos antes de entrar na escola, tais como, por exemplo, a habilidade cognitiva, o desempenho acadêmico prévio e certas características de personalidade como motivação e persistência (SOARES; RIBEIRO; CASTRO, 2001; TEDDLIE; REYNOLDS, 2000).

A variância explicada do nível da escola nos estudos revisados, entretanto, é relativamente alta: situa-se entre 33,7\% (BARBOSA; FERNANDES, 2000) e 38,9\% (FLETCHER, 1998). É importante ressaltar aqui que a variância explicada é calculada em relação ao modelo condicional, e não em relação ao modelo incondicional. Utilizar o modelo condicional em vez do modelo incondicional como ponto de referência para calcular os valores da variância explicada produz um retrato muito mais fiel da realidade no Brasil (ALVES; SOARES; 2007). No modelo condicional as variáveis relacionadas à composição e seletividade escolar são controladas simultaneamente nos diversos níveis de agregação. Recomenda-se que os pesquisadores utilizem o modelo condicional no cálculo da percentagem de variância explicada.

As pesquisas anteriormente revisadas mostram que, no Brasil, o volume de estudos que usam análise de regressão multinivel para detectar os fatores que têm impacto no desempenho escolar dos alunos está aumentando. A identificação de tais fatores é de suma importância para a elaboração de políticas públicas que possam melhorar a qualidade da educação brasileira (SOARES; CESAR; MAMBRINI, 2001). Entretanto, é bom lembrar, como afirmam Soares e Alves (2005), que os fatores identificados são relacionados entre si e que qualquer intervenção em fatores sociais, escolares ou familiares produz impacto não só sobre a proficiência do aluno, mas também sobre os outros fatores explicativos.

0 objetivo do presente estudo é identificar quais características de alunos e escolas são associadas ao desempenho em Português de alunos da 3a série do Ensino Médio no Brasil, bem como verificar se existem diferenças entre as cinco regiões geográficas do Brasil. Para atingir esses objetivos, foram considerados os alunos avaliados pelo SAEB da $3^{3}$ série do Ensino Médio do ano de 2001. Embora existam edições mais recentes do SAEB, optou-se pelo ano de 2001, pois pretende-se fazer um comparativo do desempenho das regiões do Brasil dessa década em artigos posteriores.

\section{Método}

A seguir são descritas as características distintivas dos alunos cujos dados foram analisados no presente estudo, assim como a codificação utilizada para sua diferenciação. Também são apresentados os instrumentos utilizados para a análise multinivel. 


\section{Participantes}

Para o presente estudo, no tocante à avaliação em Língua Portuguesa, foram analisados os dados de 33.962 alunos da $3^{\text {a }}$ série do Ensino Médio, distribuídos em 1.661 escolas brasileiras pesquisadas no SAEB 2001. A Tabela 1 mostra as características dos alunos incluídos na análise de regressão multinivel.

Tabela 1 - Características dos alunos incluídos na análise multinível da proficiência em Língua Portuguesa - SAEB 2001 - 3a série do Ensino Médio

\begin{tabular}{|c|c|c|c|c|}
\hline Característica & Critérios & Código & $\mathrm{N}$ & Percentagem \\
\hline \multirow{2}{*}{ Gênero } & Homens & 0 & 13.811 & $40,7 \%$ \\
\hline & Mulheres & 1 & 20.151 & $59,3 \%$ \\
\hline \multirow{2}{*}{ Etnia } & Pardos, negros e indigenas & 0 & 15.125 & $44,5 \%$ \\
\hline & Brancos e amarelos & 1 & 18.837 & $55,5 \%$ \\
\hline \multirow{7}{*}{ Atraso Escolar } & 5 anos ou mais & 5 & 2.967 & $8,8 \%$ \\
\hline & 4 anos & 4 & 3.340 & $9,8 \%$ \\
\hline & 3 anos & 3 & 2.376 & $7,0 \%$ \\
\hline & 2 anos & 2 & 3.842 & $11,3 \%$ \\
\hline & 1 ano & 1 & 6.284 & $18,5 \%$ \\
\hline & sem atraso escolar & 0 & 12.054 & $35,5 \%$ \\
\hline & 1 ou mais anos adiante da turma & -1 & 3.099 & $9,1 \%$ \\
\hline \multirow{2}{*}{ Rede Escolar } & Pública & 0 & 18.822 & $55,4 \%$ \\
\hline & Privada & 1 & 15.140 & $44,6 \%$ \\
\hline \multirow{5}{*}{ Região Geográfica } & Norte & 1 & 5.028 & $14,8 \%$ \\
\hline & Nordeste & 2 & 14.480 & $42,6 \%$ \\
\hline & Sudeste & 3 & 6.238 & $18,4 \%$ \\
\hline & Sul & 4 & 3.671 & $10,8 \%$ \\
\hline & Centro-oeste & 5 & 4.545 & $13,4 \%$ \\
\hline Total & & & 33.962 & $100,0 \%$ \\
\hline
\end{tabular}

Fonte: Os autores a partir da análise dos dados do SAEB 2001.

Observa-se que 59,3\% dos alunos analisados pertencem ao gênero feminino. Quanto à etnia dos alunos, procedeu-se à codificação das etnias parda, negra e indígena com o código 0, representando $44,5 \%$ da amostra, e as etnias branca e amarela com 0 código 1 , representado os demais 55,5\%. Quanto ao atraso escolar, ou seja, a diferença entre a idade atual e a idade ideal, os valores foram codificados de modo a indicar as categorias descritas na Tabela 1. É importante destacar que 55,4\% dos alunos da 3a série do Ensino Médio deste estudo estão, no mínimo, com um ano de atraso escolar. No que se refere às regiões geográficas, o Nordeste apresentou a maior contribuição à 
amostra, com 42,6\% dos alunos, seguido pelo Sudeste com 18,4\%, o Norte com 14,8\%, o Centro-Oeste com 13,4\% e o Sul com 10,8\% dos alunos da amostra.

\section{Instrumentos}

Além do desempenho dos estudantes em Língua Portuguesa aferida por meio de um teste cognitivo, foram considerados os questionários contextuais dos alunos, professores, diretores e escolas. Esses questionários visam a medir construtos relacionados com o aluno (NSE, trajetória escolar, apoio familiar), construtos relacionados à sala de aula (condições de trabalho, estilo pedagógico, experiência profissional) e construtos relacionados à escola (liderança do diretor, clima disciplinar, trabalho colaborativo).

\section{Análise de dados}

Com o intuito de estimar os parâmetros de grupos populacionais específicos, a população de referência foi dividida em estratos, segundo variáveis de interesse: série, unidade da federação, dependência administrativa (estadual, municipal ou particular) e localização (capital ou interior). Estatisticamente, a amostra analisada dispõe-se em uma distribuição complexa, ou seja, com probabilidades desiguais de inclusão dos elementos, além de estratificada mediante diferentes critérios. Em tais casos, Pfeffermann et al. (1998) recomendam enfaticamente a utilização de pesos amostrais, uma vez que, sem o uso de tais mensurações, as estimativas pontuais dos parâmetros, a variância e os erros-padrão podem não ser corretos. Nesse estudo, todas as estimativas de análise multinivel foram realizadas com a aplicação de pesos amostrais. Também, nas análises descritivas e nas análises fatoriais com o software SPSS (Statistical Package for the Social Sciences), versão 18.0, pesos amostrais foram utilizados.

Para a análise de regressão multinível utilizou-se o programa MLwiN em sua versão 2.02, desenvolvido por Rasbash et al. (2005). Inicialmente foi rodado o modelo nulo ou vazio que, segundo a literatura (FERRÃO, 2003; KREFT; DE LEEUW, 1998; SNIJDERS; BOSKER, 1999), serve como base para comparação com os modelos subsequentes. Em seguida, conforme sugere Fletcher (1998), pretendeu-se controlar as características relacionadas ao NSE do aluno e da escola, bem como as caracteristicas de composição escolar e familiar (escolaridade da mãe e etnia do aluno), a fim de verificar quais eram as outras fontes de variação entre as escolas passiveis de intervenção. Posteriormente, atentando para os procedimentos propostos por Hox (2010), foram incluidas as variáveis explicativas do nível micro com efeito fixo. 0 passo seguinte foi incluir as variáveis explicativas do nível macro. Em seguida, foi avaliado se alguns dos coeficientes de inclinação das variáveis explicativas do nível micro possuíam componente de variância significativa 
entre as escolas, bem como foram testadas possiveis interações das variáveis entre os níveis (efeito cross-level). Por fim, foram feitas comparações entre as regiões geográficas brasileiras.

As variáveis explicativas analisadas nos modelos construídos compreendem itens simples obtidos a partir dos questionários respondidos pelos alunos, itens compostos calculados a partir de análise dos componentes principais e valores obtidos por agregação, ou seja, valores originalmente obtidos no nível micro que foram agrupados para obter valores médios do nível da escola. Todas as variáveis explicativas usadas nesse estudo foram centralizadas na média geral e transformadas em escores padronizados z (Média $=0, D P=1$ ), com exceção das variáveis: etnia do aluno e rede escolar (ambas dicotômicas) e atraso escolar do aluno (politômico). Ressalta-se que, no questionário do aluno do SAEB, a pergunta sobre a etnia do aluno é feita da seguinte maneira: "Como você se considera? (1) Branco(a), (2) Pardo(a)/Mulato(a), (3) Negro(a), (4) Amarelo(a) e (5) Indígena. Por meio de um teste de comparação de médias, Andrade e Laros (2007) verificaram que as médias dessas categorias diferiam em relação ao desempenho escolar. Todavia, com base no teste Post Hoc os autores optaram por considerar apenas duas categorias: alunos brancos/amarelos e demais alunos. 0 presente estudo adotou esse mesmo procedimento. A variável atraso escolar, por sua vez, tem os valores extremos de -1 (um ano adiantado) e 5 ( 5 anos de atraso). Vale salientar, ainda, que algumas variáveis mensuradas no nível de aluno foram agregadas ao nível da escola, são elas: NSE, etnia do aluno, escolaridade da mãe, recursos culturais na família do aluno e cobrança e incentivo dos pais.

As seguintes variáveis são medidas multi-item (multi-item measures) baseadas na análise de componentes principais: Nível socioeconômico (NSE): composta por 16 itens (alfa $=0,87$, carga fatorial média $=0,59$; exemplos de itens: "quantidade de automóveis na residência" e "quantidade de computadores na casa"); Recursos culturais: composta por 12 itens (alfa = 0,75 , carga fatorial média $=0,51$; exemplos de itens: "o aluno tem acesso à internet em casa" e "quantidade de livros na residência do aluno"); e Cobrança e incentivo dos pais: composta por 4 itens (alfa $=0,72$, carga fatorial média $=0,69$; exemplos de itens: "os pais procuram fazer que o filho não se atrase na escola" e "os pais cobram a lição de casa do filho"). Para apreciação de todos os itens que compõem os componentes anteriormente citados consultar Andrade (2005).

\section{Resultados e Discussão}

Seguindo os passos recomendados de modelagem multinivel, inicialmente foi estimado o modelo vazio, ou seja, o modelo sem variáveis explicativas. Os resultados da estimação do modelo vazio podem ser observados na Tabela 2. 
Tabela 2 - Modelo vazio sem variáveis explicativas (M0) e modelo de referência com as variáveis de controle inseridas (M1)

\begin{tabular}{|c|c|c|c|c|c|c|}
\hline Variáveis Explicativas & \multicolumn{3}{|c|}{ Modelo Vazio (M0) } & \multicolumn{3}{|c|}{ Modelo de Referência (M1) } \\
\hline & \multicolumn{3}{|c|}{$\begin{array}{l}\text { Sem variáveis } \\
\text { Explicativas }\end{array}$} & \multicolumn{3}{|c|}{$\begin{array}{l}\text { Depois da inserção das } \\
\text { variáveis de controle }\end{array}$} \\
\hline EFEITO FIXO & Efeito & EP & Razão T & Efeito & EP & Razão T \\
\hline Intercepto & 264,90 & 1,53 & - & 274,14 & 1,37 & - \\
\hline \multicolumn{7}{|l|}{ Variáveis de controle } \\
\hline $\begin{array}{l}\text { Nivel Socioeconômico } \\
\text { agregado } \\
\text { Escolaridade da mãe do aluno } \\
\text { Etnia do aluno }\end{array}$ & & & & $\begin{array}{l}58,63 \\
6,09 \\
-4,56\end{array}$ & $\begin{array}{l}1,96 \\
0,71 \\
1,39\end{array}$ & $\begin{array}{r}29,91 \\
8,58 \\
3,28\end{array}$ \\
\hline $\begin{array}{l}\text { EFEITO RANDÔMICO - Nível } \\
2-\sigma_{u 0}^{2} \text { Variância - intercepto }\end{array}$ & 958,70 & 69,51 & 13,79 & 243,47 & 28,56 & 8,52 \\
\hline $\begin{array}{l}\text { EFEITO RANDÔMICO - Nível } \\
1-\sigma_{e}^{2} \text { Variância de } R_{i j}\end{array}$ & $1.946,08$ & 149,72 & 13,00 & $1.917,81$ & 146,07 & 13,13 \\
\hline $\begin{array}{l}\text { Correlação Intraclasse (ICC) } \\
\text { Deviance } \\
\text { Número de parâmetros } \\
\text { estimados }\end{array}$ & \multicolumn{3}{|c|}{$\begin{array}{c}0,33 \\
357.221,8 \\
3\end{array}$} & \multicolumn{3}{|c|}{$\begin{array}{c}0,11 \\
354.705,2 \\
6\end{array}$} \\
\hline $\begin{array}{l}\text { Diferença devianceM1 - } \\
\text { deviance M0 } \\
\text { Diferença de parâmetros M1 } \\
\text { - M0 } \\
\text { Teste } x^{2}\end{array}$ & & & & \multicolumn{3}{|c|}{$\begin{array}{c}2.516,6 \\
3 \\
838,9\end{array}$} \\
\hline $\begin{array}{l}\text { Variância do nível } 1 \text { explicada } \\
\text { Variância do nível } 2 \text { explicada }\end{array}$ & & & & \multicolumn{3}{|c|}{$\begin{array}{r}1,45 \% \\
74,60 \%\end{array}$} \\
\hline
\end{tabular}

Fonte: Os autores a partir da análise dos dados do SAEB 2001.

Notas: $E P$ = erro padrão; razão $T$ = tamanho do efeito dividido pelo erro padrão; a variância explicada é calculada em relação ao modelo vazio (M0).

A partir das informações referentes à variância dos níveis micro e macro, calculouse a ICC de 0,33. 0 resultado encontrado sugere que, a princípio, 33\% da variância do desempenho dos alunos no teste de Português estão associados à variabilidade entre as escolas, o que torna necessário o uso de modelos de regressão multinivel. 
Na Tabela 2 merece destaque o valor do intercepto $(264,90)$, que representa o valor médio da proficiência em Língua Portuguesa dos alunos da $3^{\text {a }}$ série do Ensino Médio. Outro resultado digno de nota é a estimativa do deviance (-2 log verossimilhança, ou -2 log likelihood) de $357.221,8$ para o modelo vazio. Este valor é utilizado como referência para comparação com os modelos posteriores. 0 deviance reflete a falta de ajuste entre os dados e o modelo (SNIJDERS; BOSKER, 1999).

Como segundo passo na modelagem multinivel foram inseridas as variáveis de controle (modelo1), a saber: NSE, escolaridade da mãe e etnia do aluno, tanto no nível do aluno quanto no nível da escola. Inicialmente foram incluidas seis variáves de controle na seguinte ordem: NSE agregado, NSE do aluno, escolaridade da mãe agregada, escolaridade da mãe do nível micro, etnia do aluno agregada e etnia do aluno no nível micro. Cabe notar que depois da inserção do NSE agregado, as variáveis NSE do aluno, escolaridade da mãe agregada e a etnia agregada não apresentaram contribuição significativa, e tomou-se a decisão de não mantê-las nos modelos posteriores.

A Tabela 2 revela os efeitos das três variáveis de controle no desempenho no teste de Português. 0 que chama atenção é um efeito muito elevado do NSE agregado: com cada acréscimo de um desvio padrão do NSE agregado o escore no teste de Português aumenta em 58,63 pontos na escala do SAEB.

Os resultados sugerem que $74,6 \%$ da variância do desempenho médio no teste de Português entre as escolas devem-se a diferenças na composição socioeconômica de seus alunos, o que indica um efeito muito grande de seleção e composição dos alunos nas escolas. Este resultado confirma o fato de que a alocação dos alunos às escolas não acontece de modo aleatório, mas sim que o NSE da família do aluno está contribuindo consideravelmente na decisão sobre qual escola o aluno vai frequentar. A inserção das variáveis de controle explicou pouca variância no nível do aluno: apenas 1,45\% da variância entre os alunos foi explicada.

Destaca-se que, mesmo controlados os efeitos de seletividade e de composição escolar, a variância do intercepto continua relativamente alta $(243,47)$ e estatisticamente significativa. A variabilidade do intercepto indica a existência de diferenças notáveis no desempenho médio no teste de Português das escolas. 0 intercepto, depois do controle para as variáveis de seletividade e composição escolar pode ser interpretado como a eficácia escolar. Antes do controle para estas variáveis, o intercepto refletiu uma parte considerável do NSE do alunado da escola. Podemos então interpretar a variância relativamente alta do intercepto do modelo 1 como um indicador da existência de diferenças substanciais na eficácia escolar no ensino da Língua Portuguesa. 
Outro resultado importante obtido da Tabela 2 é o ajuste do modelo aos dados. 0 valor do deviance do modelo 1 diminuiu 2.516,6 pontos em comparação com o deviance do modelo vazio, sendo estimados três parâmetros a mais no modelo 1 . Deste modo, o valor do teste $x^{2}$ resultou em 838,9. Este valor é obtido pelo quociente da diferença entre os deviances dos dois modelos e a diferença entre o número de parâmetros estimados $(2.516,6 \div 3=838,9)$. Este quociente deve ser maior que 1,96 (aproximadamente 2) para possuir um nível de significância de 5\%. Uma vez que 838,9 é bem maior que 1,96, este modelo é bem mais ajustado que o anterior, com um índice de significância menor que 1\%.

Em seguida foi realizada uma comparação entre as diferentes regiões geográficas do pais em relação ao modelo vazio (M0) e ao modelo de referência (M1). Os resultados são apresentados na Tabela 3.

Tabela 3 - Proficiência média em Língua Portuguesa (SAEB 2001 - 3a série do Ensino Médio), variâncias dos níveis macro e micro e a ICC para as cinco regiões do Brasil, antes e depois da inserção das variáveis de controle

Antes da inserção das variáveis de controle

\begin{tabular}{l|c|c|c|c}
\hline \multicolumn{1}{c|}{ Região } & Proficiência Média & Variância nível 2 & Variância nível 1 & ICC \\
\hline Norte & 266,44 & $1.098,75$ & $1.841,99$ & 0,37 \\
\hline Nordeste & 258,00 & $1.125,39$ & $1.930,78$ & 0,37 \\
\hline Sudeste & 287,33 & $1.096,96$ & $1.938,19$ & 0,36 \\
\hline Sul & 288,32 & 844,87 & $1.881,96$ & 0,31 \\
\hline Centro-Oeste & 284,38 & 855,49 & $1.907,94$ & 0,31 \\
\hline
\end{tabular}

Depois da inserção das variáveis de controle

\begin{tabular}{l|c|c|c|c}
\hline \multicolumn{1}{c|}{ Região } & Proficiência Média & Variância nível 2 & Variância nível 1 & ICC \\
\hline Norte & 269,28 & 275,91 & $1.826,34$ & 0,13 \\
\hline Nordeste & 273,92 & 261,49 & $1.905,96$ & 0,12 \\
\hline Sudeste & 278,54 & 253,84 & $1.918,11$ & 0,12 \\
\hline Sul & 276,29 & 215,45 & $1.848,39$ & 0,10 \\
\hline Centro-Oeste & 277,22 & 236,55 & $1.895,92$ & 0,11 \\
\hline
\end{tabular}

Fonte: Os autores a partir da análise dos dados do SAEB 2001.

A Tabela 3 mostra os valores obtidos após a construção de modelos específicos para cada região geográfica, antes e depois da inserção das variáveis de seletividade e composição escolar. Observa-se, no primeiro caso, que entre 31\% (Sul e Centro-Oeste) e 37\% (Norte e Nordeste) da variância entre as escolas podem ser explicados pelos modelos construídos. No segundo caso, após a inserção das variáveis de seletividade e composição escolar, estes índices variam entre 10\% (Sul) e 13\% (Norte). 
A inspeção da Tabela 3 revela que a região Sul tem o desempenho médio mais elevado no teste de Português, antes da inserção das variáveis de controle. Além de ter o escore médio mais alto, a região Sul também é a região que apresenta a menor variabilidade no teste Português, ou seja, todas as escolas da região Sul têm um escore médio relativamente alto nesta prova.

Digno de nota é também o fato de que as escolas na região Nordeste (NE) mostram maior variabilidade no escore médio no teste Português. A divisão da variância do nível da escola pelo somatório da variância do nível da escola e nível do aluno permite o cálculo da ICC: no teste de Português podemos observar valores entre 0,31 e 037. Estes valores estão em sintonia com os valores relatados por Ferrão et al. (2001).

Merece destaque a diferença observada entre os valores de intercepto para as regiões, antes e depois da inserção das variáveis de controle. Depois de controlar para as variáveis de seletividade e composição escolar, a eficácia escolar média das cinco regiões do Brasil ficou menos desigual, com valores ao redor de 277 para o Sul, o Sudeste e o Centro-oeste, e valores ao redor de 270 para o Norte e o Nordeste. 0 maior diferencial na Tabela 3, entretanto, é observado na variância do nível da escola: os valores são marcadamente reduzidos após a inserção das variáveis de controle, consequentemente reduzindo o efeito escola para cerca de um terço do valor antes observado.

De acordo com outros estudos multinível de fatores associados ao desempenho escolar (ALBERNAZ; FERREIRA; FRANCO, 2002; ANDRADE; LAROS, 2007; SOARES, 2004), uma vez controlados os efeitos da seletividade e composição das escolas, ainda existe suficiente variância que pode ser explicada tanto pelos efeitos do nível macro quanto pelos efeitos do nível micro. Foram estimados, primeiramente, os efeitos do nível micro, considerando a amostra total de respondentes do banco (modelo 2). As seguintes variáveis deste nível foram incluídas no modelo: recursos culturais na familia do aluno, atraso escolar, cobrança e incentivo dos pais, repetência, absenteísmo discente, abandono escolar, aluno gosta de estudar Lingua Portuguesa, aluno trabalha, aluno faz dever de casa, e, por fim, aluno usa computador no dever de casa.

Verificou-se que os coeficientes de regressão das dez variáveis incluídas no modelo foram estatisticamente significativos (razão $T>1$,96). A variável que mais afetou o desempenho escolar dos alunos foi recursos culturais na familia do aluno, seguida de atraso escolar. Verifica-se que a cada aumento de um desvio-padrão da escala de recursos culturais, o desempenho médio dos alunos aumenta em 16,78 pontos. Com cada aumento de um ano de atraso escolar, 0 desempenho médio dos alunos piora em 8,92 pontos. 
Em seguida, foram inseridas as variáveis explicativas referentes ao nivel da escola (modelo 3). Duas das três variáveis referentes ao nível macro foram mensuradas no nível do aluno e agregadas para o nivel da escola, a saber: percentagem de repetência na turma e percentagem de alunos que trabalham na turma. A única variável originalmente mensurada no nível da escola foi rede escolar (pública ou privada). As variáveis incluídas no modelo que afetam negativamente no desempenho escolar são: percentagem de repetentes e percentagem de alunos que trabalham na turma. Por outro lado, a variável rede escolar apresentou um efeito positivo no desempenho em Língua Portuguesa.

No passo seguinte do processo de modelagem multinivel foi verificado se algum dos coeficientes de regressão das variáveis explicativas do nível micro tinham um componente significativo de variância, ou seja, diferente de zero, entre as unidades do nível macro. As variáveis que não apresentaram coeficiente de regressão com efeito aleatório foram estimadas novamente com os coeficientes de regressão fixos. A melhoria no ajuste deste modelo em comparação ao modelo anterior foi extremamente significativa $\left(X^{2}\right.$ tendendo a $\infty$ ). Deve-se observar que ambos os modelos (modelo 3 e modelo 4) possuem o mesmo número de parâmetros estimados, uma vez que se inseriu o componente aleatório do atraso escolar mas removeu-se a variável rede escolar, que não mais se mostrou significativa. Dessa forma, esse último modelo foi considerado mais adequado. 0 resultado de que a variável atraso escolar tem um coeficiente de regressão aleatório quer dizer que o efeito desta variável não é igual para todas as escolas.

0 último passo executado na modelagem multinivel foi o de verificar os efeitos de interação entre os níveis (efeito cross-level). Dois efeitos de interação foram encontrados: entre atraso escolar e percentagem de repetentes na turma, bem como entre atraso escolar e percentagem de alunos que trabalham na turma. 0 primeiro efeito de interação indica que o atraso escolar tem um efeito maior em escolas com uma maior percentagem de estudantes que repetem o ano do que em escolas com poucos estudantes nessa situação. A segunda interação indica que o atraso escolar tem um efeito maior em escolas com maior porcentagem de estudantes que trabalham em comparação com escolas com menor porcentagem de estudantes que trabalham. Os resultados aqui encontrados devem ser confrontados com resultados de outras pesquisas, a fim de que sejam corroborados ou refutados. A análise do deviance sugere que este último modelo, o modelo 5, que é o modelo final, mostra ajustar-se melhor aos dados em comparação com os modelos anteriores. No modelo final deste estudo foram explicados, no mínimo, 40,6\% da variância do nível da escola e 14,1\% da variância do nível do aluno, tomando como referência o modelo depois da inserção das variáveis de controle.

As Tabelas 4, 5 e 6 mostram comparações entre os modelos finais obtidos separadamente por região geográfica. Observa-se que, em diferentes regiões, variáveis de controle e variáveis explicativas podem não ser significativas. Na região Centro-Oeste, por exemplo, as seguintes variáveis não tiveram um efeito significativo: escolaridade da mãe, percentagem de repetentes na turma, e os dois efeitos de interação (Tabela 4). 
Tabela 4 - Modelo de regressão multinivel final das regiões Centro-Oeste e Norte da proficiência em Língua Portuguesa -SAEB 2001 - 3a série do Ensino Médio

\begin{tabular}{|c|c|c|c|c|c|c|}
\hline \multirow{3}{*}{$\begin{array}{l}\text { Variáveis Explicativas } \\
\text { EFEITO FIXO }\end{array}$} & \multirow{2}{*}{\multicolumn{3}{|c|}{$\begin{array}{l}\text { Modelo Multinivel Final } \\
\text { REGIÃO CENTRO-OESTE }\end{array}$}} & \multirow{2}{*}{\multicolumn{3}{|c|}{$\begin{array}{c}\text { Modelo Multinível Final } \\
R E G I \tilde{O} O \text { NORTE }\end{array}$}} \\
\hline & & & & & & \\
\hline & Efeito & EP & Razão T & Efeito & EP & Razão T \\
\hline Intercepto & 284,62 & 1,40 & - & 286,29 & 3,28 & - \\
\hline \multicolumn{7}{|l|}{ Variáveis de controle } \\
\hline Nível Socioeconômico agregado & 26,19 & 3,70 & 7,08 & 26,65 & 3,59 & 7,42 \\
\hline Escolaridade da mãe do aluno & & & & 1,67 & 0,76 & 2,20 \\
\hline Etnia do aluno & 3,00 & 1,33 & 2,26 & & & \\
\hline \multicolumn{7}{|l|}{ Variáveis do nível do aluno } \\
\hline $\begin{array}{l}\text { Recursos culturais na família } \\
\text { do aluno }\end{array}$ & 19,62 & 1,80 & 10,90 & 16,09 & 1,69 & 9,52 \\
\hline Atraso escolar do aluno & $-7,72$ & 0,64 & 12,06 & $-9,81$ & 0,52 & 18,87 \\
\hline $\begin{array}{l}\text { Cobrança e incentivo dos pais } \\
\text { do aluno }\end{array}$ & $-8,92$ & 0,95 & 9,39 & $-7,94$ & 0,82 & 9,68 \\
\hline Repetência do aluno & $-6,10$ & 0,75 & 8,13 & $-5,23$ & 0,54 & 9,69 \\
\hline Absenteísmo discente & 2,62 & 0,92 & 2,85 & 4,15 & 0,66 & 6,29 \\
\hline Abandono escolar & $-6,76$ & 0,69 & 9,80 & $-6,95$ & 0,65 & 10,69 \\
\hline $\begin{array}{l}\text { Aluno gosta de estudar Língua } \\
\text { Portuguesa }\end{array}$ & 2,82 & 0,65 & 4,34 & 2,81 & 0,66 & 4,26 \\
\hline Aluno trabalha & $-2,07$ & 0,79 & 2,62 & & & \\
\hline Aluno faz dever de casa & 3,43 & 0,66 & 5,20 & 3,57 & 0,61 & 5,85 \\
\hline $\begin{array}{l}\text { Aluno usa computador no dever } \\
\text { de casa }\end{array}$ & $-2,79$ & 0,65 & 4,29 & $-2,47$ & 0,63 & 3,92 \\
\hline
\end{tabular}

Variáveis do nível da turma

Percentagem de repetentes na turma

Percentagem de alunos que trabalham na turma

$\begin{array}{llllll}-12,01 & 3,12 & 3,85 & -17,32 & 3,41 & 5,08\end{array}$

Variáveis de interação

Atraso escolar $x$ Percentagem de repetentes na turma

Atraso escolar x Percentagem de alunos que trabalham

EFEITO ALEATÓRIO - Nível $2-\sigma_{u 0}^{2}$

Variância - Intercepto

Variância - Inclinação atraso escolar

\begin{tabular}{ccc|ccc}
157,13 & 26,61 & 5,90 & 229,92 & 35,11 & 6,55 \\
11,57 & 4,93 & 2,35 & 9,45 & 3,42 & 2,76 \\
\hline $1.654,96$ & 36,09 & 45,86 & $1.534,05$ & 31,79 & 48,26 \\
\hline $\begin{array}{c}46.844,77 \\
17\end{array}$ & & \multicolumn{3}{|c}{$\begin{array}{c}51.458,98 \\
17\end{array}$} \\
\hline
\end{tabular}

Efeito ALEATÓRIO - Nível 1 -

$\sigma_{e}^{2}$ Variância de $R i j$

Deviance

Número de parâmetros

estimados

$4,34 \quad 0,85$

Fonte: Os autores a partir da análise dos dados do SAEB 2001. 
Vale ressaltar que, tanto na região Centro-0este quanto na região Norte, no modelo final somente 17 parâmetros foram estimados, versus 22 parâmetros no modelo final para a amostra nacional. Outro resultado que chama a atenção na Tabela 4 é que, na região Norte, existe mais variância do intercepto do que na região Centro-Oeste, ou seja, existe mais variabilidade na eficácia escolar para ensinar a Língua Portuguesa na região Norte do que na região Centro-Oeste. Os modelos das regiões Nordeste e Sul podem ser vistos na Tabela 5 .

Tabela 5 - Modelo de regressão multinivel final das regiões Nordeste e Sul da proficiência em Língua Portuguesa - SAEB 2001 - $3^{\text {a }}$ série do Ensino Médio

\begin{tabular}{|c|c|c|c|c|c|c|}
\hline Variáveis Explicativas & \multicolumn{3}{|c|}{ Modelo Multinivel Final } & \multicolumn{3}{|c|}{ Modelo Multinível Final } \\
\hline & \multicolumn{3}{|c|}{ REGIÃO NORDESTE } & \multicolumn{3}{|c|}{ REGIÃO SUL } \\
\hline Efeito Fixo & Efeito & EP & Razão T & Efeito & $\mathrm{EP}$ & Razão T \\
\hline Intercepto & 282,94 & 1,03 & - & 284,81 & 1,78 & - \\
\hline \multicolumn{7}{|l|}{ Variáveis de controle } \\
\hline Nível Socioeconômico agregado & 33,85 & 2,17 & 15,60 & 21,84 & 4,06 & 5,38 \\
\hline Escolaridade da mãe do aluno & 2,58 & 0,45 & 5,73 & 4,12 & 0,97 & 4,25 \\
\hline Etnia do aluno & 1,69 & 0,70 & 2,41 & & & \\
\hline \multicolumn{7}{|l|}{ Variáveis do nível do aluno } \\
\hline $\begin{array}{l}\text { Recursos culturais na família } \\
\text { do aluno }\end{array}$ & 15,75 & 0,99 & 15,91 & 19,03 & 2,12 & 8,98 \\
\hline Atraso escolar do aluno & $-8,49$ & 0,27 & 31,44 & $-9,43$ & 0,79 & 11,94 \\
\hline $\begin{array}{l}\text { Cobrança e incentivo dos pais } \\
\text { do aluno }\end{array}$ & $-8,74$ & 0,50 & 17,48 & $-5,50$ & 1,05 & 5,24 \\
\hline Repetência do aluno & $-5,77$ & 0,34 & 16,97 & $-4,14$ & 0,81 & 5,11 \\
\hline Absenteísmo discente & 3,09 & 0,39 & 7,92 & 4,36 & 1,11 & 3,93 \\
\hline Abandono escolar & $-6,05$ & 0,42 & 14,40 & $-6,90$ & 0,78 & 8,85 \\
\hline $\begin{array}{l}\text { Aluno gosta de estudar Língua } \\
\text { Portuguesa }\end{array}$ & 1,88 & 0,43 & 4,37 & 3,41 & 0,70 & 4,87 \\
\hline Aluno trabalha & $-1,31$ & 0,39 & 3,36 & $-3,70$ & 0,88 & 4,20 \\
\hline Aluno faz dever de casa & 5,25 & 0,36 & 14,58 & 3,83 & 0,70 & 5,47 \\
\hline $\begin{array}{l}\text { Aluno usa computador no } \\
\text { dever de casa }\end{array}$ & $-3,06$ & 0,38 & 8,05 & $-1,70$ & 0,71 & 2,39 \\
\hline \multicolumn{7}{|l|}{ Variáveis do nível da turma } \\
\hline $\begin{array}{l}\text { Percentagem de repetentes } \\
\text { na turma }\end{array}$ & $-6,20$ & 1,96 & 3,16 & $-14,98$ & 4,18 & 3,58 \\
\hline $\begin{array}{l}\text { Percentagem de alunos que } \\
\text { trabalham na turma }\end{array}$ & $-12,09$ & 2,27 & 5,33 & $-6,68$ & 3,20 & 2,09 \\
\hline
\end{tabular}


(continuação)

\begin{tabular}{|c|c|c|c|c|c|c|}
\hline \multicolumn{7}{|l|}{ Variáveis de interação } \\
\hline \multirow{2}{*}{$\begin{array}{l}\text { Atraso escolar x Percentagem } \\
\text { de repetência na turma } \\
\text { Atraso escolar x Percentagem } \\
\text { de alunos que trabalham na } \\
\text { turma }\end{array}$} & \multirow[b]{2}{*}{2,42} & \multirow[b]{2}{*}{0,57} & \multirow[b]{2}{*}{4,24} & \multirow[b]{2}{*}{3,09} & \multirow[b]{2}{*}{1,12} & \multirow[b]{2}{*}{2,76} \\
\hline & & & & & & \\
\hline \multirow{4}{*}{$\begin{array}{l}\text { Efeito ALEATÓRIO - Nível } \\
2-\sigma_{u 0}^{2} \\
\text { Variância - Intercepto } \\
\text { Variância - Inclinação atraso } \\
\text { escolar }\end{array}$} & \multirow{4}{*}{$\begin{array}{c}210,75 \\
3,66\end{array}$} & \multirow{4}{*}{$\begin{array}{c}21,76 \\
1,66 \\
\end{array}$} & \multirow{4}{*}{$\begin{array}{l}9,69 \\
2,20\end{array}$} & \multirow{4}{*}{$\begin{array}{c}125,18 \\
6,17 \\
\end{array}$} & \multirow{4}{*}{$\begin{array}{c}24,13 \\
4,94 \\
\end{array}$} & \multirow{4}{*}{$\begin{array}{l}5,19 \\
1,25 \\
\end{array}$} \\
\hline & & & & & & \\
\hline & & & & & & \\
\hline & & & & & & \\
\hline $\begin{array}{l}\text { Efeito ALEATÓRIO - Nível } 1 \text { - } \\
\sigma_{e}^{2} \text { Variância de } R_{i j}\end{array}$ & $1.619,77$ & 19,74 & 82,06 & $1.635,20$ & 39,60 & 41,29 \\
\hline Deviance & \multirow{2}{*}{\multicolumn{3}{|c|}{$\begin{array}{c}148.848,30 \\
20\end{array}$}} & \multirow{2}{*}{\multicolumn{3}{|c|}{$\begin{array}{c}37.765,61 \\
19\end{array}$}} \\
\hline $\begin{array}{l}\text { Número de parâmetros } \\
\text { estimados }\end{array}$ & & & & & & \\
\hline
\end{tabular}

Fonte: Os autores a partir da análise dos dados do SAEB 2001.

Um dos resultados da Tabela 5 que vale ressaltar é que existe uma grande diferença entre o ajuste dos dados ao modelo na região Sul e na região Nordeste, a saber, entre um deviance de $148.848,3$ e $37.765,6$. Isso significa que o modelo final se ajusta muito melhor aos dados da região Sul do que aos dados da região Nordeste. Outro resultado que merece destaque na inspeção da Tabela 5 é o baixo valor da variância do intercepto da região Sul. Aparentemente, na região Sul existe relativamente pouca variabilidade na eficácia escolar. Por sua vez, os modelos representativos da região Sudeste e do Brasil está representado na Tabela 6.

Tabela 6 - Modelo de regressão multinível final da região Sudeste e para Brasil da proficiência em Língua Portuguesa - SAEB 2001 - 3a série do Ensino Médio

\begin{tabular}{|c|c|c|c|c|c|c|}
\hline Variáveis Explicativas & \multicolumn{3}{|c|}{ Modelo Multinível Final } & \multicolumn{3}{|c|}{ Modelo Multinivel Final } \\
\hline & \multicolumn{3}{|c|}{ REGIÃO SUDESTE } & \multicolumn{3}{|c|}{ BRASIL } \\
\hline Efeito Fixo & Efeito & $\mathrm{EP}$ & Razão T & Efeito & $\mathrm{EP}$ & Razão T \\
\hline Intercepto & 288,47 & 1,33 & - & 285,57 & 1,24 & - \\
\hline \multicolumn{7}{|l|}{ Variáveis de controle } \\
\hline $\begin{array}{l}\text { Nivel Socioeconômico } \\
\text { agregado }\end{array}$ & 26,46 & 3,30 & 8,02 & 30,84 & 1,28 & 24,09 \\
\hline Escolaridade da mãe do aluno & 1,58 & 0,74 & 2,14 & 2,07 & 0,30 & 6,90 \\
\hline Etnia do aluno & 3,40 & 1,18 & 2,88 & 1,98 & 0,48 & 4,13 \\
\hline \multicolumn{7}{|l|}{ Variáveis do nível do aluno } \\
\hline $\begin{array}{l}\text { Recursos culturais na família } \\
\text { do aluno }\end{array}$ & 20,30 & 1,63 & 12,45 & 17,58 & 0,66 & 26,64 \\
\hline
\end{tabular}


(continuação)

\begin{tabular}{|c|c|c|c|c|c|c|}
\hline Atraso escolar do aluno & $-9,93$ & 0,58 & 17,12 & $-8,92$ & 0,20 & 44,60 \\
\hline $\begin{array}{l}\text { Cobrança e incentivo dos pais } \\
\text { do aluno }\end{array}$ & $-7,93$ & 0,77 & 10,30 & $-8,19$ & 0,33 & 24,82 \\
\hline Repetência do aluno & $-5,92$ & 0,57 & 10,39 & $-5,56$ & 0,24 & 23,17 \\
\hline Absenteísmo discente & 4,12 & 0,78 & 5,28 & 3,50 & 0,28 & 12,50 \\
\hline Abandono escolar & $-5,45$ & 0,58 & 9,40 & $-6,21$ & 0,26 & 23,88 \\
\hline $\begin{array}{l}\text { Aluno gosta de estudar Língua } \\
\text { Portuguesa }\end{array}$ & 3,80 & 0,55 & 6,91 & 2,75 & 0,25 & 11,00 \\
\hline Aluno trabalha & $-3,09$ & 0,63 & 4,90 & $-1,86$ & 0,26 & 7,15 \\
\hline Aluno faz dever de casa & 3,28 & 0,52 & 6,31 & 4,21 & 0,23 & 18,30 \\
\hline $\begin{array}{l}\text { Aluno usa computador no } \\
\text { dever de casa }\end{array}$ & $-3,12$ & 0,53 & 5,89 & $-2,77$ & 0,24 & 11,54 \\
\hline \multicolumn{7}{|l|}{ Variáveis do nível da turma } \\
\hline $\begin{array}{l}\text { Percentagem de repetentes } \\
\text { na turma }\end{array}$ & $-11,01$ & 3,51 & 3,14 & $-9,77$ & 1,61 & 6,07 \\
\hline $\begin{array}{l}\text { Percentagem de alunos que } \\
\text { trabalham na turma }\end{array}$ & $-15,40$ & 2,96 & 5,20 & $-10,46$ & 1,24 & 8,44 \\
\hline \multicolumn{7}{|l|}{ Variáveis de interação } \\
\hline $\begin{array}{l}\text { Atraso escolar x Percentagem } \\
\text { de repetência na turma }\end{array}$ & & & & 1,27 & 0,47 & 2,70 \\
\hline $\begin{array}{l}\text { Atraso escolar x Percentagem } \\
\text { de alunos que trabalham na } \\
\text { turma }\end{array}$ & 5,25 & 0,96 & 5,47 & 2,75 & 0,36 & 7,64 \\
\hline \multicolumn{7}{|l|}{ EFEITO ALEATÓRIO - Nível } \\
\hline \multicolumn{7}{|l|}{$2-\sigma_{u 0}^{2}$} \\
\hline \multicolumn{7}{|l|}{ Variância - Intercepto } \\
\hline \multirow{2}{*}{$\begin{array}{l}\text { Variância - Inclinação atraso } \\
\text { escolar }\end{array}$} & 173,10 & 24,65 & 7,02 & 191,25 & 11,98 & 15,96 \\
\hline & 8,23 & 3,79 & 2,17 & 5,02 & 1,24 & 4,05 \\
\hline \multicolumn{7}{|l|}{ EFEITO ALEATÓRIO - Nível } \\
\hline \multicolumn{6}{|l|}{ Variância de $R_{i j}$} & 125,68 \\
\hline Deviance & & \multicolumn{3}{|c|}{$349.361,8$} \\
\hline $\begin{array}{l}\text { Número de parâmetros } \\
\text { estimados }\end{array}$ & \multicolumn{3}{|c|}{20} & \multicolumn{3}{|c|}{22} \\
\hline
\end{tabular}

Fonte: Os autores a partir da análise dos dados do SAEB 2001.

Inspecionando-se a primeira coluna da Tabela 6, merece destaque que apenas um efeito não está presente no modelo final para a região Sudeste: a interação entre atraso escolar e percentagem de repetência na turma. Essa interação também não foi significativa nas demais regiões. A partir da segunda coluna da Tabela 6 pode-se comparar o modelo multinivel para o Brasil com os modelos para cada uma das regiões. 
A comparação do modelo final das cinco regiões do Brasil chama atenção que o intercepto do modelo final exibe o valor mais alto na região Sudeste $(288,47)$, e o mais baixo na região Nordeste $(282,94)$. A variância do intercepto mostra o valor mais elevado no Norte $(229,92)$ e o mais baixo $(125,18)$ no Sul. 0 que é mais digno de nota na comparação do modelo final para as cinco regiões do Brasil é o resultado de que o NSE agregado tem mais impacto no desempenho em Português na região Nordeste (efeito de 33,85 ) e menos impacto na região Sul (efeito de 21,84 ). Entretanto, os valores do modelo final da região Nordeste (Tabela 5) devem ser interpretados com muita cautela, uma vez que o ajuste do modelo aos dados desta região é muito inferior em comparação ao ajuste do modelo final aos dados das demais regiões. Depois da região Nordeste, é a região Norte a que mostra o maior impacto do NSE contextual (efeito de 26,65).

No modelo final para Brasil os erros-padrão dos efeitos são menores em comparação aos das regiões. Isso significa que existe menos incerteza sobre os valores verdadeiros dos parâmetros e, portanto, os intervalos de confiança são menores. 0 modelo final nacional é composto por 18 variáveis: uma dependente e 17 independentes. A variável dependente, a proficiência em Língua Portuguesa, está colocada na escala do SAEB. 0 valor da variável dependente no modelo final $(285,57)$ é o valor médio dos alunos da $3^{a}$ série do Ensino Médio se todas as variáveis independentes assumirem o valor zero. As 17 variáveis independentes no modelo final podem ser classificadas da seguinte maneira: três variáveis de controle, dez variáveis do nível micro, duas variáveis do nível macro e duas variáveis de interação entre os níveis. No modelo final, consta uma variável independente cujo coeficiente de regressão é aleatório.

\section{Considerações Finais}

0 objetivo central do presente estudo foi ampliar o conhecimento sobre fatores que têm efeito sobre o desempenho em Lingua Portuguesa dos alunos do Ensino Médio. De acordo com as recomendações de Soares e Andrade (2006), o efeito do nível socioeconômico (NSE) dos alunos e da escola (NSE contextual) foi controlado no processo de modelagem multinivel. Os autores acima referidos assinalam que, no Brasil, não se deve estudar a realidade educacional sem considerar o NSE dos alunos e o NSE contextual. Verificou-se que as variáveis de controle explicam $75 \%$ da variância do desempenho na prova da Língua Portuguesa no nível da escola. Entre as variáveis de controle, a maior contribuição no modelo final foi o da variável nível socioeconômico da escola. Como afirmam Soares e Alves (2003) é um verdadeiro constrangimento o fato de que, no Brasil, o nivel socioeconômico tem uma influência tão grande na aprendizagem do aluno.

No modelo multinivel final para o Brasil o desempenho em Português foram explicados, no mínimo, 40,6\% da variância do nível da escola e 14,1\% da variância do nivel do aluno, tomando como referência o modelo depois da inserção das variáveis de controle. A comparação do intercepto das cinco regiões do Brasil antes da inserção 
das variáveis de controle evidencia valores entre 258,0 para o Nordeste e 288,3 para o Sul; depois de inserir as variáveis de controle os interceptos assumam valores entre 269,3 para o Norte e 278,5 para o Sudeste. Pode ser concluido que a desigualdade entre regiões em relação ao desempenho médio das escolas em Língua Portuguesa é fortemente relacionada com o nível socioeconômico dos alunos e das escolas.

Das variáveis relacionadas ao nível do aluno, verificou-se que as que mais afetam o desempenho em Português são: Recursos culturais na família do aluno e Atraso escolar. A cada aumento de um desvio padrão de Recursos culturais na família do aluno o desempenho médio dos alunos aumentou em 16,6 pontos na escala do SAEB. Um aumento de um ano de Atraso escolar significa uma diminuição de 9,7 pontos. Baseados nesses resultados pode-se afirmar que deveriam ser operacionalizadas políticas públicas com o objetivo de reduzir o atraso escolar. No planejamento pedagógico das escolas deveriam ser incentivadas aulas de reforço escolar para que alunos com deficit de aprendizagem possam acompanhar as aulas regulares a fim de diminuir o atraso escolar.

Verificou-se que das variáveis do nível da escola, a que mais afeta o desempenho em Português é Percentagem de repetentes na turma. Essa variável é tratada como aproximação (proxy) de uma variável mensurada no nível da escola, mesmo sendo originalmente obtidas no nivel do aluno. Ressalta-se que seria melhor utilizar informações coletadas diretamente no nivel da escola em vez de estimar estas informações por meio do processo de agregação de dados do nível do aluno. Entretanto, na avaliação do SAEB 2001, estes dados não foram coletados.

Como afirmam Soares e Alves (2006), os fatores que determinam o desempenho cognitivo do aluno pertencem a três grandes categorias: a estrutura escolar, a família e características do próprio aluno. 0 presente estudo identificou fatores de todas as três categorias, sendo que os fatores com mais impacto no desempenho em Língua Portuguesa de cada categoria são: Percentagem de alunos que trabalham na turma (estrutura escolar), Recursos culturais na familia do aluno (familia) e Atraso escolar (características do aluno). Esperamos que os fatores identificados por este estudo possam contribuir na melhoria da qualidade do ensino em Língua Portuguesa na educação básica do Brasil.

\section{Referências}

ALVES, T. G. A.; SOARES, J. F. As pesquisas sobre o efeito das escolas: contribuições metodológicas para a sociologia da educação. Sociedade e Estado, Brasília, v. 22, n. 2, p. 435-473, 2007.

ALBERNAZ, A.; FERREIRA, F. H. G.; FRANCO, C. Qualidade e eqüidade na educação fundamental brasileira. Rio de Janeiro: PUC-Rio, 2002. 
ANDRADE, J. M. de. Construção de um modelo explicativo de desempenho escolar: um estudo psicométrico e multinível com dados do SAEB. 2005. 160f. Dissertação (Mestrado em Psicologia Social e do Trabalho) - Universidade de Brasília, Brasília, 2005.

ANDRADE, J. M. de; LAROS, J. A. Fatores associados as desempenho escolar: estudo multinivel com dados do SAEB/2001. Psicologia: Teoria e Pesquisa, Brasília, v. 23, n. 1, p. 33-42, 2007.

BARBOSA, M. E. F.; FERNANDES, C. Modelo multinível: uma aplicação a dados de avaliação educacional. Estudos em Avaliação Educacional, São Paulo, n. 22, p. 135-153, 2000.

BRYK, A. S.; RAUDENBUSH, S. W. Hierarchical Linear Models: Applications and data analysis methods. $2^{\text {nd }}$ ed. Newbury Park: Sage Publications, 2002.

CREEMERS, B.; SCHEERENS, J. Developments in the educational effectiveness research programme. International Journal of Educational Research, Cambridge, v. 21, n. 2, p. 125-139, 1994.

FERRÃO, M. E. Introdução aos modelos de regressão multinível em educação. Campinas: Komedi, 2003.

FERRÃO, M. E. et al. O SAEB - Sistema Nacional de Avaliação da Educação Básica: objetivos, características e contribuições na investigação da escola eficaz. Revista Brasileira de Estudos de População, Rio de Janeiro, v. 18, n. 102, p. 111-130, 2001.

FERRÃO, M. E.; FERNANDES, C. 0 efeito-escola e a mudança - dá para mudar? Evidencias da investigação brasileira. Revista Eletrônica Ibero-americana sobre Qualidade, Eficácia e Mudança em Educação (REICE), Madri, n. 1, v. 1, p. 1-13, 2003.

FLETCHER, P. R. À procura do ensino eficaz. Rio de Janeiro: Ministério da Educação e Cultura, Departamento da Avaliação da Educação Básica, 1998.

HOX, J. J. Multilevel Analysis Techniques and Applications. $2^{\text {nd }}$ ed. Mahwah, New Jersey: Lawrence Erlbaum Associates, 2010.

JESUS, G. R. de; LAROS, J. A. Eficácia escolar: regressão multinivel com dados de avaliação em larga escala. Avaliação Psicológica, Campinas, v. 3, n. 2, p. 21-31, 2004.

KISH, L. Survey sampling. New York: Wiley, 1965. 
KREFT, I. G. G.; DE LEEUW, J. de. Introducing multilevel modeling. Newbury Park, CA: Sage Publications, 1998.

PFEFFERMANN, D. et al. Weighting for unequal selection probabilities in multilevel models. Journal of the Royal Statistical Society, Charlottesville, v. 60, p. 23-40, 1998.

RASBASH, J. et al. A user's guide to MLwiN: version 2.0. London: Centre for Multilevel Modeling, Institute of Education, 2005.

SOARES, J. F. 0 efeito escola no desempenho cognitivo de seus alunos. Revista Eletrônica Ibero-americana sobre Qualidade, Eficácia e Mudança em Educação (REICE), Madri, v. 2, n. 2, p. 83-104, 2004.

SOARES, J. F.; ALVES, M. T. G. Desigualdades raciais no sistema brasileiro de educação básica. Educação e Pesquisa, São Paulo, v. 29, n. 1, p. 147-165, 2003.

SOARES, J. F.; ANDRADE, R. J. de. Nivel socioeconômico, qualidade e eqüidade das escolas de Belo Horizonte. Ensaio: avaliação e políticas públicas em educação, Rio de Janeiro, v. 14, n. 50, p. 107-126, jan./mar. 2006.

SOARES, J. F.; CESAR, C. C.; MAMBRINI, J. Determinantes de desempenho dos alunos do ensino básico brasileiro: evidências do SAEB de 1997. In: FRANCO, C. (Org.). Avaliação, ciclos e promoção na educação. Porto Alegre: Artmed, 2001. p.121-154.

SOARES, J. F.; RIBEIRO, L. M.; CASTRO, M. C. Valor agregado de instituições de ensino superior em Minas Gerais para os cursos de Direito, Administração e Engenharia Civil. Dados, Rio de Janeiro, v. 44, n. 2, p. 1-28, 2001.

SOARES, T. M. Modelo de três níveis hierárquicos para a proficiência dos alunos de 4a série de língua portuguesa do SIMAVE/PROEB-2002. Revista Brasileira de Educação, Rio de Janeiro, v. 29, p. 73-87, 2005.

SNIJDERS, T. A. B.; BOSKER, R. J. Multilevel analysis: an introduction to basic and advanced multilevel modeling. Newbury Park: Sage Publications, 1999.

TEDDLIE, C. T.; REYNOLDS, D. The international handbook of school effectiveness research. London: Falmer Press, 2000.

WOLFF, L. Educational assessments in Latin America: the state of the art. Applied Psychology: an International Review, Baden-Wuerttemberg, v. 53, n. 2, p. 192-214, 2004.

Recebido em: 17/09/2009

Aceito para publicação em: 07/05/12 